\title{
International Experience, Principles and Conditions for the Transition to a "Green Economy"
}

\author{
Dusan Kudelas ${ }^{1, *}$, Eugen Domru ${ }^{2}$, Adrian Stoianov ${ }^{2}$, and Dénes Peters ${ }^{3}$ \\ ${ }^{1}$ Technical University of Kosice, Faculty of Mining, Ecology, Process Control and Geotechnologies, \\ Letná 9, 04200 Kosice, Slovak Republic \\ ${ }^{2}$ University of Petroșani, Faculty of Mining, 332006 Universității Str. 20 Petroșani, Romania \\ ${ }^{3}$ Budapest University of Technology and Economics, 1111 Müegyetem rakpart 1-6 Budapest, \\ Hungary
}

\begin{abstract}
Proceeding from the general ideology of the sustainable development concept, the issues of determining the long-term social and environmental consequences of modern economic development are fundamental, and the success of implementing the ideas of economic modernization and energy efficiency depends on the active position of state and regional authorities. To move to the path of sustainable development, carefully coordinated actions in all spheres of the economy are needed. It requires a model of an organizational and economic mechanism that would ensure the transition to a "green economy", the reorientation of economic, environmental and social institutions to priority areas. Clearly, at the moment, there is an urgent need for moving to an economic model that will improve human well-being, while preserving resources and not exposing future generations to significant environmental risks. To conduct an effective environmental policy and to assess the overall effectiveness of "green" growth, it is proposed to develop a model for ensuring a transition to a "green economy", which will allow understanding the level and coordination of activities, the scale and boundaries of their impact, and most comprehensively process information on possible projected risks and possible negative effects (pollution, degradation of ecosystems).
\end{abstract}

\section{Introduction}

The world economy, trying to overcome the financial crisis of 2008-2009 (the so-called "crisis of creating imaginary riches and the irrational use of money"), is still in the zone of uncertainty about the further development vector. The situation is aggravated by a whole range of synergistically reinforcing phenomena of anthropogenic and purely economic nature (the universal principle of "cumulative causality" according to T. Veblen): climate change; increase in prices for basic food products; the widespread deterioration of biodiversity and the supply of ecosystem services; the drop in availability of water resources; increase in the number of technogenic accidents; inefficient use of massive

\footnotetext{
* Corresponding author: dusan.kudelas@gmail.com
} 
injections of liquid funds into the world financial system; increasing privatization of income and socialization of costs and risks, etc. [1-2]. All this complicates and aggravates pressing social problems and leads to further job cuts, violation of labor standards, insecurity and poverty, and this gives a new round of pressure on nature. This confirms once again that the economy is only part of a complex natural and social system, the components of which are interconnected, but not always predictable in their evolution.

Despite all the successes and achievements, today there is still a need for so many resources that go beyond the capabilities of our planet. According to the 2010 report of the World Wide Nature Fund, the living planet index (estimates the state of biodiversity) shows a 30\% decrease compared to 1970, and the ecological footprint of mankind (human need for natural resources) since 1966, on the contrary, almost doubled. If our requirements for the planet continue to increase at the same pace, by 2030 we will need the equivalent of two planets to maintain the old way of life, and by $2050-2.8$ of the planet. It turned out that as national incomes grew (according to the rule of Kuznets), certain indicators of the environmental performance in the country may improve, but environmental efficiency and sustainability often continue to fall [3].

It is obvious that fundamentally new steps are needed, a transition to the development concept that will solve the social, financial, fuel and climate problems in a comprehensive manner and achieve not only quantitative growth, but also significant qualitative and real improvements.

\section{Materials and Methods}

The theory of growth limits, according to which, with the preservation of current trends in growth and pollution of the environment, a global catastrophe is possible, calling for "zero growth" and the refusal to build new enterprises, practically does not take into account the progressive nature of scientific and technical progress.

But due to this and a number of other theories, environmental restrictions in the last quarter of the XX century became seriously taken into account by scientists and developers of government programs. Additional fundamental studies have been carried out, which showed the need to change the principles of management [4-7]. Following the scientists, authoritative international organizations and individual politicians adopted a number of policy documents and declarations calling for making scientific recommendations for sustainable development an everyday practice. Examples of this are the 1987 report of the United Nations World Commission on the Environment; The agenda for the XXI century, adopted in Rio de Janeiro in 1992; The Millennium Declaration of 2000; The Johannesburg Plan of Implementation of 2002; Decisions of the Economic and Social Commission for Asia and the Pacific (ESCAP) 2005; Plan "20-20-20" of the Brussels Energy and Climate Summit of the EU in 2008; The Paris Declaration on Environmentally Friendly Growth in 2009; The United Nations Environment Program (UNEP) in 2009 - all aimed at supporting national and regional initiatives to improve the efficiency and sustainability of the use of resources and production processes. But despite all the importance and informative value, the listed initiatives are of a declarative and recommendatory nature, often not supported by appropriate financing.

Many countries that have experienced a recession and massive loss of jobs in the current crisis have engaged in a more active search for new models for further development. As such a cardinal model, a model of a "green" economy was proposed, i.e. such an economic system that is aimed at increasing the society well-being and social guarantees and simultaneously reducing environmental risks and deficits. According to M. Kenneth, only a "green" economy is capable of stabilizing economic systems and balancing human interests, nature and efficient use of resources [8]. 
Thus, the 40th World Economic Forum 2010, held in Davos under the slogan "Improve the state of the planet: rethink, reschedule, rebuild the world", announced a new global course for a "green" economy (the term replaced the previously existing concept of "sustainable development"), as the only way of future development. By integrating numerous analytical and policy proposals, the forum also announced that the coming decade (2010-2020) will be the decade of "green economy".

The transition to the "green" economy and liquidation of poverty was also discussed at the three-day United Nations Conference on Sustainable Development in 2012, which will be called Rio +20 on the occasion of the anniversary of the 1992 United Nations Conference on Environment and Development. The concept of "green" economy becomes a "new" course that can overcome the crisis and that is supported by the scientific community, international organizations, governments, environmental and technological standards which are getting stringent, investments in relevant sectors and infrastructure, innovative business and consumer requirements.

By analogy with Roosevelt's course, a globally coordinated large-scale comprehensive package of incentive measures to revive the world economy and lay the foundation for future economic prosperity and prosperity was called a new "green" course. But if Roosevelt's course was a course of economic growth (aimed at strengthening quantitative indicators), then the new "green" course has other emphases - this is mainly the course of sustainable economic development (the growth of quality indicators). In addition, F. Roosevelt's course was empirical and was implemented in the "manual" mode. In contrast, as it was mentioned above, the concept of the "green" economy has deep political and economic roots: it creatively integrates the ideas of wellbeing theory and their modern version - theories of economic growth and quality of life, the theory of the Kondratiev major cycles, the theory of limits of economic growth, the theory of innovation development.

\section{Results and Discussion}

The old "model of a resource-intensive economy" will lead to increased costs and lower productivity. The ongoing crises are indicators of this model and, finally, form the idea of a new model of a "green economy" in which material prosperity is not inevitably ensured by increasing environmental risks, environmental deficits and social inequality.

The concept of a "green" economy is a model that leads to better health and social justice for the population, as well as to a significant reduction of hazardous environmental impacts and a reduction in the ecological deficit. Thus, the "green" economy, in its simplest form, can be considered as a low-carbon, resource-saving and socially inclusive model of the economy.

The concept of a "green economy" does not replace the concept of sustainable development, but there is widespread recognition that achieving sustainability is almost entirely based on obtaining economic law.

Most interpretations of the "green" economy recognize that ecosystem, the economy, the well-being of the population and related types of capital are closely connected.

The United Nations Environment Program (UNEP) defines the "green" economy as a tool that enhances human well-being and social equity and significantly reduces the adverse environmental impact and risks of environmental degradation.

The OECD has developed and introduced the concept of "green growth", defining it as the maximum provision of economic growth and development without affecting the quantity and quality of natural assets and using the growth potential that arises from the transition to a "green" economy. That is, "green growth" is the growth of GDP, which is subject to "green" conditions and focuses on "green" sectors as new growth engines. 
"Green" growth represents both a problem and an opportunity for the labor market, which, in turn, is the main factor in the possible "green" growth. The dynamics of the response and proper functioning of labor markets play a key role in facilitating the transition to the "green" and resource-efficient economy. The transition to a sustainable economy leads to changes (some of them are quite serious) in the structures of employment and in the professional profiles of workers.

Basic principles of the green economy of UNEP:

1. Justice and objectivity, both within the framework of one generation, and between generations;

2. Coherence with the principles of sustainable development;

3. Preventive approach to social and environmental impacts;

4. Evaluation of natural and social capital, for example, internationalization of external costs, green accounting, lifetime costs and management improvement;

5. Sustainable and efficient use of resources, consumption and production;

6. The need to achieve the existing macroeconomic goals by creating green jobs, liquidation of poverty, increasing competitiveness and growth in key sectors.

Most countries in the world have recently intensified their environmental policies to move away from a traditional model in which environmental protection is considered a burden on the economy, to a model in which ecology is recognized as the engine of development, i.e. to the "green" economy.

In Mexico, for example, it is planned to build energy-efficient buildings, to cut carbon emissions by half by 2050, and to introduce a program helping households to replace old household devices with new models with higher energy efficiency.

The USA provides for $80 \%$ reduction of harmful emissions by 2050 , using solar power plants, $65 \%$ of the energy consumed by the country and $35 \%$ of heat will be produced. The US investment plan for the development of environmentally friendly technologies is aimed not only at improving the environmental situation, but also creating up to 5 million jobs [3].

South Korea, which has chosen the concept of "green" growth as a national strategy, focuses on "green" industry, energy and investment, "green" modes of transport, alternative sources of fresh water, waste processing technologies, development of parks, and development of rivers within the city. Various projects that the ministries carried out independently were combined into a single package to avoid budget expenditures for secondary purposes.

Almost all EU countries have developed new "green" measures in the energy sector, in the development of public transport and infrastructure, construction of eco-cities, and in the development of systems for the recycling of cars. The EU has recently adopted standards for Euro-6 automobile exhausts and the introduction of new Euro-7 is already being prepared. Multimillion subsidies are allocated to customers for the purchase of electric vehicles. Britain has adopted the economy of green technologies as a strategy for its national development and recently announced its "green" projects aimed at creating 100,000 new jobs.

Japan plans to expand the volume of the market of environmental technologies by 2015 with the aim of increasing the labor market by 2.2 million jobs. The key factor was advanced technologies, social mechanisms and traditions that are in harmony with the environment.

In China, it is planned to receive 15\% (now 9\%) of electricity from renewable sources by 2020 , and reduce the carbon intensity of the economy by $45 \%$. However, foreign scholars do not share the optimism of their Chinese colleagues. They came to the conclusion that the increase in emissions in China will continue until 2020, and the reduction will begin only around 2030 [3]. This conclusion is exacerbated by the growth trends of some of the most important sectors of Chinese industry and, above all, the 
automobile industry. The level of annual production of cars in China has exceeded 10 million units, significantly passing over Germany and the United States.

The proclaimed new course on economic recovery on the "green" basis is necessary not only to prevent the worst consequences of excessive use of natural resources, depletion of ecosystems and climate change, but also to create and consolidate a wide range of highpaying innovative jobs. A real sign of the economic stability of the country and one of the most important macroeconomic indicators is employment. According to experts, by 2030 , about 20 million only "direct" jobs will be created in environmentally friendly enterprises, without taking into account the multiplier of employment and clustering of "green" processes in the economy, so that we can talk about hundreds of millions of potential "green" jobs. This is supported by the following factors:

1. The direction of investments for the development of resource-efficient and environmentally friendly industry, achievement of sustainable energy security, the creation of a new industrial infrastructure with low emissions and ensuring environmental protection has a high employment potential.

2. Investments should be directed not to the old, polluting industries of the short-term economy of yesterday, but to new "green" sectors of the economy that will solve the urgent problems. Economic education and retraining is especially in demand because "green" development programs, green investments, eco-innovation, green crediting, green accounting, green marketing, new principles of taxation and financing are what a modern specialist will have to face during his activity.

3. For people with an average qualification, the repair and restoration work of traditional water supply systems is another source of job creation. Similarly, investments in sustainable forest management can create tens of millions of new jobs.

4. Global prospects for the development of ecological tourism.

5. The construction sphere of a new generation can accommodate millions of people. The first echo-cities are being built, designed to create comfortable living conditions and reduce the harmful impact on nature. But in traditional cities and settlements it is necessary to create energy-efficient and resource-efficient buildings with zero emissions, the "green" modernization of apartments is gaining popularity, which will revive the construction sector.

6. There will be an energy efficient transport with low emissions (hybridization and fleet electrification have already begun). Increasing production of vehicles with low emissions will create millions of new jobs in the world. In addition, it is possible to create several tens of millions of related jobs in different countries of the world in such areas as cleaning and supply of fuel, sale, repair and utilization of cars. Investments in clean and efficient public urban transport also promote secondary employment.

7. There is an active use of new industries, including multimedia entertainment, which generate revenues, create jobs and markets without harming the environment. For example, the use of computer graphics in film and on test benches saves resources.

8. To develop "green" products, equipment and services R\&D will be required. Innovation activity will increase, large-scale project and expert work will begin, and scientific control over compliance with tougher environmental standards will increase too.

For the transition to the "green" economy, a variety of market-oriented software and economic tools are offered:

- transferring eco-technologies from more developed countries to less developed ones; - a policy of public procurement that encourages the production of environmentally friendly products;

- increase in public investment in infrastructure consistent with the principles of sustainable development (including public transport, renewable energy sources, construction of energy efficient buildings) and natural capital; 
- targeted state support for research and development related to the creation of environmentally friendly technologies, etc.

As part of the implementation of the "green" development, fiscal reforms are being carried out, ecologically dangerous ones are being abolished and environmentally friendly subsidies are being introduced, the practice of environmental public procurement is expanding, and trade barriers are being eliminated along the path of environmentally impeccable goods and services.

Among other promotion measures for the construction of the "green" economic future may be called: economic studies supporting the transition; involvement of national and local administrative bodies, enterprises, the public; education and training of personnel to take the "green" jobs; improvement of the accounting system for natural resources; integration of the goals of the "green" economy and sustainable consumption and production policies into national development strategies, etc.

\section{Conclusion}

The development of "green" economy means the implementation of the following actions.

Further development of environmental legislation and application of the most successful practice in the management of air, water, soils and waste. Expansion of the sector of organic agriculture, introduction of certificates for organic products in the country and an increase in imports of organic products. Promotion of decisions on eco-innovations based on high research potential. Use of legislative and economic tools to mitigate the effects of climate change and support adaptation measures. Introduction of energy efficiency measures in cities. Attracting foreign direct investment and creating "green" jobs.

\section{References}

1. R. Costanza, H.E. Daly, Ecol. Modelling, 38, 1 (1987)

2. R. Costanza, Ecol. Econ., 1, 1 (1989)

3. A. Brief, International Journal of Humanities and Social Science, 4, 155 (2015)

4. Z. M. Nazarova, Yu. A. Leonidova., Proceedings of Higher Schools, Geology and Exploration, 2, 82 (2017)

5. M. Cehlár, P. Varga, Z. Jurkasová, M. Pašková, Acta Montanistica Slovaca, 15 (SPEC.ISSUE 2), 132-138 (2011)

6. B. Sály, J. Janocko, S. Jacko, V. Jureňa, I. Hlavaty, New results in the mature east slovakian basin based on $3 D$ and $2 D$ seismic data interpretation and sequence stratigraphy, Society of Petroleum Engineers, 68th European Association of Geoscientists and Engineers Conference and Exhibition, incorporating SPE EUROPEC 2006 (EAGE, 2006)

7. K. Y. Hoon, Y. Y. Chih, C. W. Ibbs, California management review, 51:2, 51 (2009)

8. M. Kenneth, The Green Economy (ManCity, Manchester, 1998) 